\title{
Effect of Iron deficiency on glycation ofhemoglobin in non diabetics
}

\author{
Manzura Rustum Mulani ${ }^{1 *}$,Pandharinath Shankarrao Gawali ${ }^{2}$
}

\begin{abstract}
${ }^{2}$ Department of Internal Medicine, JIIU'S IIMSR Medical College \& Hospital ,Warudi, Taluka, Badnapur, Jalna, Maharashtra
\end{abstract}

Correspondence to:

Miss manzura Rustum Mulani

JIIU'S IIMSR Medical College \& Hospital,

Warudi, Taluka, Badnapur, Jalna

431202 Aurangabad-Jalna Road, Jalna, Maharashtra

Email: manzuramulani@gmail.com

How to cite this article:

Mulani MR, Gawali PS. Effect of Iron deficiency on glycation of hemoglobin in non diabetics. Ann. Clin. Chem. Lab. Med. 2016:2(2); 4-7

DOI: http://dx.doi.org/10.3126/acclm.v2i2.14824

(C) 2016 Nepalese Association for Clinical Chemistry

\section{(c) (1) (2)}

This work is licensed under a Creative Commons Attribution-Share Alike $\mathbf{4 . 0}$ International License.

\section{Abstract \\ BACKGROUND}

Hemoglobin $\mathrm{A} 1 \mathrm{C}(\mathrm{HbA} 1 \mathrm{c})$ has been adopted by physicians as a surrogated for monitoring glycemic control. The use of $\mathrm{HbA1C}$ for the diagnosis of diabetes is now widely advocated despite caveats to its use. HbA1c concentrations are influenced by several factors including red blood cells (RBC) turnover. There are many types of anemia that affect glycated hemoglobin (HbA1c) values, but iron deficiency anemia (IDA) one of the most common. Further research needs to focus on the mechanistic reasons why $\mathrm{HbA} 1 \mathrm{c}$ is higher in IDA. The study attempts to discern clinical differences in $\mathrm{HbA} 1 \mathrm{c}$ levels in patients with IDA, compared to patients without IDA \& showing the direction of such differences.

\section{METHODS}

50 non diabetic anemic patients and 50 age matched healthy subjects were involved in this study. Hematological investigations were done and fasting \& post prandial (PP) glucose and $\mathrm{HbA} 1 \mathrm{c}$ level were measured in all the subjects.

\section{RESULTS}

The mean $\mathrm{HbA} 1 \mathrm{c}$ [9.10 $\pm 1.08 \%$ ] in the patients with IDA was higher than that in the control non anemic group $[5.21 \pm 0.45 \%][P<0.001]$ There was no differences in the levels of fasting and PP glucose between the IDA \& the control groups. [P>0.05]

\section{CONCLUSIONS}

$\mathrm{HbA1c}$ is likely to be affected by IDA with a spurious increase in $\mathrm{HbA} 1 \mathrm{c}$ values, conversely non IDA may lead to confusion when diagnosing diabetes using HbA1c. This article clearly identifies especially the types of anemia likely to have significantly impact on the reliability $\mathrm{HbA1c}$.

KEY WORDS: HbA1c, hemoglobin, IDA 


\section{Introduction}

Chronic hyperglycemia is the hallmark of diabetes mellitus [DM] [1].HbA1c is used as gold standard for monitoring glycemic controls and as a predictor of diabetic complications [2]. HbA1c is a hemoglobin variant that is formed when glucose bind covalently to the $\beta$ chain of $\mathrm{HbA}$ [3]. The number " $1 \mathrm{C}$ " represents the orders of $\mathrm{Hb}$ detection on chromatography. The normal life span of the erythrocyte is 120 days [4]. The glycation of $\mathrm{Hb}$ occurs over the entire 120 days life span of erythrocyte.

$\mathrm{HbA} 1 \mathrm{c}$ measures the binding of circulating glucose to $\mathrm{Hb}$ protein within RBC. Higher levels of glucose in the blood, contribute to more binding and consequently higher levels of glycated $\mathrm{Hb}$. The major form of glycated $\mathrm{Hb}$ is $\mathrm{HbA} 1 \mathrm{c}$ [5].

The international Expert committee and American Diabetes Association (ADA) has recommended using $\mathrm{HbA1C}$ to diagnosis DM [6].The traditional role of $\mathrm{HbA} 1 \mathrm{c}$ is the most prominent biomarker for assessing and management of glycemic status of people with diabetes [7].Over the years many health care providers have come to view the $\mathrm{HbA1c}$ values as a "magic number" that comprises all the information required for blood glucose concentration to prevent complications in people with diabetes, the concept "the lower the better" was considered a tempting approach.HbA1c was considered as " an abnormal $\mathrm{Hb}$ in diabetes " by Samuel Rohbar.

Human $\mathrm{Hb}$ in its structural and functional features in the most extensively studied protein. The major component of its $\mathrm{HbA}_{0}\left(\alpha_{2} \beta_{2}\right)$ comprises over $90 \%$ the total protein with the other two minor components being $\mathrm{Hb}$ genes. $\mathrm{HbA} 1 \mathrm{c}$ is the most abundant minor components arises from spontaneous, non enzymatic, post translational modification reaction of $\mathrm{HbA}_{0}$. $\mathrm{HbA1C}$ on the contrary, in unique set of conditions represents the formation of glycosylated form of human $\mathrm{Hb}$ [8]. Glycated $\mathrm{Hb}$ is produced by $\mathrm{a}$ ketoamine reaction between glucose and $\mathrm{NH}_{2}$ terminal of both $\beta$ chain of the hemoglobin molecule [9].HbA1c is majorly affected by the blood glucose level alone. However, certain studies have proven that, the HbA1c levels are altered by various other existing factors along with or without diabetes, especially that of IDA [10]. Which is major public health problem in developing countries like India. According to World Health Organization (WHO) IDA is one of the most common types of anemia found worldwide [11].The WHO estimated that 2.1 billion people globally have IDA, which is approximately $30 \%$ of the world population at that time. The prevalence of IDA is higher in low \& high income countries,
Adolescents, children and women are the most susceptible. In these countries, diabetes is also a rapidly increasing issue [12].In India, it is estimated that $52 \%$ of non-pregnant women of reproductive age are anemic [13].

The RBC turnover can be decreases too and this will increases glycation rate of the $\mathrm{Hb}$ [14].The pathogenesis of anemia varies depending on the cause and influence on $\mathrm{HbA} 1 \mathrm{c}$ is also variable. The value of HbA1c influenced by certain physiological and pathological condition depends on 3 main factors, the $\mathrm{Hb}$ present in reticulocytes when there are released from the bone marrow, the glycation rate is a function as the erythrocyte age (since $\mathrm{Hb}$ glycation rate of $\mathrm{Hb}$ is a function of glucose concentration to which $\mathrm{Hb}$ is exposed) and the mean age of erythrocytes in the circulation [15].

Anemia and its effect on $\mathrm{HbA1c}$ has not been studied extensively. Although IDA is a commonly encountered disease in clinical practice. In the current study we performed a cross sectional analysis to investigate the association between IDA and HbA1c levels in adults.The study attempted to discern clinical difference in HbA1c levels in patients with anemia compared to non anemic populations as well as to quantify and show the direction that asglucose is covalently bound to $\mathrm{HbA} 1 \mathrm{c}$ glycosylated $\mathrm{Hb}, \mathrm{HbA} 1 \mathrm{c}$ levels in non diabetic iron deficiency anemic population is significantly higher than in non diabetic non anemic population.

\section{Methods}

Blood sample were obtained from 50 anemic patients of the mean age of patients (37.44 \pm 5.11 years) among which 12 were males and 38 were females and 50 age matched healthy subjects. The anemic patients were recruited from the medicine Outpatients Department of our institute, medical college \& Hospital Warudi. District Jalana, Maharashtra, India from September 2015 to February 2016, constituted material for this study. The anemic patients their peripheral blood smears (mostly microcytic hypochromic) which suggested IDA, their hematological investigation like $\mathrm{PCV}, \mathrm{MCV}, \mathrm{MCH} \& \mathrm{MCHC}$. The blood samples were drawn after on overnight fast. A sysmax automated hematology analyzer was used for the whole blood count $\mathrm{Hb}$, haematocrit (Hct), mean carpuscular volume (MCV) and mean carpuscular hemoglobin $(\mathrm{MCH})$ and fasting \& PP glucose levels by GOD-POD method.The $\mathrm{HbA} 1 \mathrm{c}$ levels were determined by SDA1c Care System based on the Immunoassay and reflectometry technology and the peripheral blood smear were examined in all the patients. The anemic 
patients were selected, based on their $\mathrm{Hb}$ levels $(\mathrm{Hb}<11.0 \mathrm{~g} / \mathrm{dl})$ and the peripheral blood smears (mostly microcytic hypochromic) which suggested IDA, their hematological investigation like PCV, MCV, $\mathrm{MCH} \& \mathrm{MCHC}$. serum $\mathrm{F} \& \mathrm{PP}$ glucose levels. The study assumed a consistent $\mathrm{HbA} 1 \mathrm{c}$ assay method at the study center over the study period.Patients with history of acute chronic blood loss, hemolytic anemia, haemoglobinopathies, kidney diseases, diabetes, pregnancy, chronic alcohol ingestion and impair glucose tolerance, gestational diabetes, history of endocrinopathy with affect for glycemic control. $\mathrm{Hb}$ concentration $<6.0 \mathrm{~g} / \mathrm{dl}$ or $>11 \mathrm{~g} / \mathrm{dl}$.

\section{Results}

All the results are presented as mean \pm SD. The statistical significance of the difference between the groups was evaluated by the students ' $\mathrm{t}$ ' test. The correlation was assessed by the partial correlation analysis. A P value of 0.05 was considered statistically

\begin{tabular}{|c|c|c|}
\hline Parameters & $\begin{array}{c}\text { IDA (n=50) } \\
\text { mean } \pm \text { SD }\end{array}$ & $\begin{array}{c}\text { Controls } \\
\text { (n=50) } \\
\text { mean } \pm \text { SD }\end{array}$ \\
\hline Age & $37.44 \pm 5.11$ & $37.54 \pm 4.77$ \\
\hline FBSL(mg/dl) & $83.38 \pm 6.57$ & $81.80 \pm 5.64$ \\
\hline PPBSL(mg/dl) & $114.88 \pm 8.33$ & $116.67 \pm 8.57$ \\
\hline Hb (gm/dl) & $8.07 \pm 1.07$ & $12.27 \pm 1.00$ \\
\hline MbA1c (\%) & $9.10 \pm 1.08$ & $5.21 \pm 0.45$ \\
\hline HCT (\%) & $30.40 \pm 3.36$ & $38.53 \pm 5.05$ \\
\hline MCV fl & $71.23 \pm 5.02$ & $82.43 \pm 2.37$ \\
\hline & $21.66 \pm 2.54$ & $31.28 \pm 1.41$ \\
\hline & & \\
\hline & & \\
\hline
\end{tabular}

significant. All the parameters which were tested in both the groups have been reported in (Table No.1). of 50 patients 38 (76\%) were females \& 12(24\%) were males. The mean age of the patient (37.44 \pm 5.11 years) The F and PP blood glucose level confirmed the Table No. 1: Comparision of various parameters between patients and control

non diabetic status. The peripheral blood smears showed a hypochromic microcytic picture.The $\mathrm{HbA1c}$ levels were significantly increased among the IDA patients as compared to those in the controls. The mean $\mathrm{HbA} 1 \mathrm{c}$ levels in anemic patients were significantly increased among the IDA patients as compared to those in the controls. The mean $\mathrm{HbA1c}$ $(9.10 \pm 1.08 \%)$ level in patients with IDA was higher than in the control group. $(5.21 \pm 0.45 \%) \quad(P<0.001)$ There were no difference in the levels of fasting and PP glucose between the IDA and the control groups (P>0.05).

\section{Discussion}

We observed a significant increase in the $\mathrm{HbA1c}$ concentration in the IDA patients, when compared to that of healthy controls. We found a significant reduction in the activity of $\mathrm{Hb}$ among the IDA patients. (Table no. $1 \mathrm{P}<0.001$ )According to some investigators, the increase in the glycated $\mathrm{Hb}$ in nondiabetic anemic patients has been mainly attributed to the decrease in the $\mathrm{Hb}$ levels in these patients. ElAgouza et al 2002 [16].This study has got a significant relevance because IDA is very highly prevalent in a tropical country like India [17].The current study was also supported by Brooks et al [18].IDA was associated with higher concentration of $\mathrm{HbA1c}$. Higher $\mathrm{HbA1c}$ concentration in iron deficiency non diabetic adults which decreased to normal after iron replacement Hansen et al [19].The mechanism that lead to increase glycosylated HbA1c level in IDA was not clear, the explanation provided in the studies are just assumptions. There is a dearth of literature on $\mathrm{HbA} 1 \mathrm{c}$ levels in the anemic population. There are a few documented studies on this matter the finding of which are at best, in consistent.But it was postulated that the quaternary structure of the $\mathrm{Hb}$ molecule was altered in IDA. This allowed the $\beta$ globin chain to be more readily glycosylated in the face of low $\mathrm{Hb}$ or iron levels.Sluiter et al postulated that formation of glycosylated $\mathrm{Hb}$ is irreversible with $\mathrm{Hb}$ and the $\mathrm{HbA} 1 \mathrm{c}$ in a RBC increase with the cell age [20]. IDAis chronic disorder, RBC production will decrease leading to anemia and a longer life span of red blood cells in the circulation. This would lead to an increase $\mathrm{HbA1c}$ [21].Dr. Chittaranjan S. Yajnik of king Edward Memorial Hospital Research Center in Pune, India wrote that," A1c concentration depends not only on prevailing glycemia but also the life span of 
erythrocyte [22].Iron deficiency increases erythrocyte survival and therefore disproportionate elevated $\mathrm{HbA1c}$ concentrations at a given glycemic level.

Among the 10 genetic loci associated with $\mathrm{HbA} 1 \mathrm{c}$ level in Caucasians, three are in loci associated with fasting glucose level, where as seven are in genes related to erythrocyte physiology. A decision to use $\mathrm{HbA1c}$ is must also consider the probability that the patient has $\mathrm{Hb}$ variants, that may interfere with the analysis.IDA has been known to cause a rise in $\mathrm{HbA} 1 \mathrm{c}$ of up to $2 \%$ and this has been shown to be reversed with iron supplementation. Some studies show that, HbA1c levels are increase in IDA and attempted to explain on the basis of both modification to the structure of $\mathrm{Hb}$ and levels of HbA1c in old and new red blood cells [23]. Hence extending target $\mathrm{HbA} 1 \mathrm{c}$ values to certain anemia may be erroneous due to potential differences in glycation rates and some physiological challenges. (markedly decreased red cell survival)

\section{Conclusion}

From this study it can be concluded that, glycation of $\mathrm{Hb}$ is definitely affected in anemia particularly IDA,

\section{References}

1. American Diabetes Association. Diagnosis and classification of diabetes mellitus. Diabetes Care 2010;33(Suppl 1):S62-S69.

2. Reddy et al. Clinical applications of glycosylated hemoglobin. $\mathrm{L}$ clin sc: Res 2012; 2:22-33.

3. Weykamp C, John W, Mosca A. A review of the challenge in measuring HbA1c, J Diabetes Sci Technol. 2009;3(3):439-45.

4. Bunn HF, Haney DN, Kamin S, Gabbay KH, Gallop PM. The biosynthesis of human hemoglobin A1c.Slow glycosylation of hemoglobin in vivo. J Clin Invest 1976; 57:1652-59.

5. Dipiro JT, Talbert RL, Yee GC, Matzke GR, Wells BG, Posey LM, eds. Pharmacotherapy: A Pathophysiologic Approach $7^{\text {th }}$ ed. New York, NY: McGraw-Hill; 2008.

6. Shekhar $\mathrm{H}$ et al. Effect of iron deficiency on glycation ofhaemoglobin in nondiabetics. ISJN 2014;5(3): 477-79.

7. American Diabetes Association. Diagnosis and classification of diabetes mellitus. Diabetes Care 2010;33 (Suppl 1):S62-9.

8. Emma English, Iskandar Idris et al. The effect of anemia and abnormalities of erythrocyte indices on $\mathrm{HbA1C}$ analysis:a systematic review;Diabetiology Springer Verlag Berlin Heidelberg 2 april 2015.

9. Rolf Hinzmann et al. What do we need beyond hemoglobin A1c to get complete picture of glycemia in people with diabetes? Int j Med Sci 2012;9(8):665-81.

10. Rahbar S, Blumenfeld O, Ranney HM. Studies of an unusual hemoglobin in patients with diabetes mellitus. Biochem Biophys Res Commun 1969;36:838-43.

11. Chandalia HB , Krishnaswamy PR, Glycated hemoglobin. Current science.2002; 83(12):1522-32.

12. De Rosa MC, Sanna MT, Messana I, Castagno-la M, Galtieri A, Tellone E,et al., Glycated human haemoglobin (HbA1c): Functional characteristics and molecular modeling studies. Biophys Chem. 1998; 72:323-35.

13. Coban E, Ozdogan M, Timuragaolgu A. The effect of iron deficiency anemia on the levels of hemoglobin $A 1 C$ in Nondiabetic patients. Acta Haematol. 2004; 112: $126-28$. even in non diabetic patients. It is found that HbA1c level in IDA increased almost in linear proportion and increase in HbA1c level is statistically significant.

It is also seen that, as soon as IDA is treated, HbA1c levels tend to reach to normal levels, changes in abnormal levels of HbA1c to normal levels individually suggested that anemia has been treated sufficiently.

The present case lies at the intersection of clinical chemistry, medicine and hematology. This study has contributed to a better understanding of its appropriate use and interpretation.

It so the IDA has to be corrected before any diagnostic or therapeutic decision was made based on the $\mathrm{HbA1C}$ level. Also the clinician should or must considered the overall patient profile and a number of local variations and disorders as anemia, so HbA1c cannot be used as sole and independent test to diagnosis diabetes mellitus. But the clinician must consider the overall profile of the patient before taking into consideration the abnormal $\mathrm{HbA1c}$ value.

\section{Conflicts of interest}

None declared.

14. Nadia Hussain, $\mathrm{Hb} \mathrm{A} 1 \mathrm{c}$ and IDA our understanding through the decades; Rom J Diabetes Nutr Metab Dis 22(3):289-296.

15. WHO, World-Wide Prevalence of Anaemia, 1993 to 2005, WHO, Geneva, Switzerland,2008.

16. National Nutritional Monitoring Bureau. NNMB Micronutrient Survey. National Institute of Nutrition, Hyderabad,2002.

17. Jung II Son, Sang Youl Rhee et al, HbA1c may be an inadequate diagnostic tool for DM in anemic subjects. DMJ 2013; 37:343-48.

18. El-Agouza I, Abu Shola A , Sirdah M.The effect of iron defiiciency naemia on the levels of the haemoglobin subtypes: the possible consequences in a clinical diagnosis. Clin Lab Haematol2002; 24:285-89.

19. Brooks AP, Metcalfe J, Day JL, Edwards MS. Iron defiiciency and glycosylated haemoglobin A1. Lancet.1980;19(ii):141.

20. Hansen PG, Eriksen J, Andersen TM, Olesen L. Glycosylatedhae-moglobin (HbA1c) in iron and vitamin B12 deficiency. J. Intern. Med.1990;227:133-36.

21. Higgins T, Boehr SD.Challenges in HbA1c analysis ans reporting: an interesting case illustrating the many pitfalls. Clin Biochem.2008; 41(13):1104-6.

22. High $\mathrm{A} 1 \mathrm{C}$ in some subjects may not indicate prediabetes, Diabetes Care Online Feb 8,2012.

23. Soranzo N, Sanna S, Wheeler E, Gieger C, Radke D, Dupuis J et al. Common Variants at 10 genomic loci influence $\mathrm{HbA} 1 \mathrm{c}$ via glycemic and non glycemic pathway Diabetes 2010;59(12):3229-39.

24. Reddy A, Sachan A et al. Clinical applications of glycosylated haemoglobin. J Clin Sci Res 2012;2;22-33.

25. Kaiasker V, Sudhamadhuri et al. Effect of IDA on glycosylated $\mathrm{Hb}$ levels in non diabetic Indian adults. Int J Med Health Sci. 2014;3(1):40-43. 